\title{
Growth-selective survival in piscivorous larvae of Japanese Spanish mackerel Scomberomorus niphonius: early selection and significance of ichthyoplankton prey supply
}

\author{
Jun Shoji $^{1,2, *}$, Masaru Tanaka ${ }^{1}$ \\ ${ }^{1}$ Laboratory of Estuarine Ecology, Field Science Education and Research Center, Kyoto University, Sakyo, \\ Kyoto 606-8502, Japan \\ ${ }^{2}$ Present address: Takehara Fisheries Research Station, Center for Education and Research of Field Science, \\ Hiroshima University, Minato-machi 5-8-1, Takehara, Hiroshima 725-0024, Japan
}

\begin{abstract}
Scombrid fishes are considered to have adopted a survival strategy characterized by fast growth and the ability to consume large prey at an early age. Variability in feeding condition can significantly affect larval growth as early as the post first-feeding stage and may control growth-related survival during the early larval stage. Through otolith microstructure analysis, growth-selective survival was demonstrated for post first-feeding larvae of Japanese Spanish mackerel Scomberomorus niphonius, which exhibit exclusive piscivory, a high growth rate, and low tolerance to starvation. Larvae and juveniles were repeatedly collected in the Seto Inland Sea in June and July from 1997 to 1999. Growth trajectory back-calculated using otolith microanalysis was compared between the survivors (SV) captured in July and the presumed original population (OP) captured in June. Selection for fast-growing larvae was evident during the $5 \mathrm{~d}$ after first feeding (Days 5 to 10 ). More than $90 \%$ of the SV had a mean growth rate during Days 5 to $10\left(G_{5-10}\right)>0.8 \mathrm{~mm} \mathrm{~d}^{-1}$, and those with $G_{5-10}$ $<0.8 \mathrm{~mm} \mathrm{~d}^{-1}$ rarely survived the period. Intensity of selection differed among 3 years. A less intense selection was observed in 1999 when the larval cohort experienced higher prey concentrations and $G_{5-10}$. Laboratory experiments demonstrated that 1 to $2 \mathrm{~d}$ starvation retarded the larval growth during the following larval period, and supported the conclusion that fluctuation in ichthyoplankton prey abundance alters larval survival probability by affecting the larval growth rate within a short period subsequent to first feeding.
\end{abstract}

KEY WORDS: Scombrids · Spanish mackerel $\cdot$ Scomberomorus $\cdot$ Larvae $\cdot$ Growth-selective survival Otolith microstructure $\cdot$ Piscivory

\section{INTRODUCTION}

Fast growth increases survivorship during early life stages of fish in a variety of natural ecosystems (Post \& Prankevicius 1987, Hovenkamp 1992, Hare \& Cowen 1997, Sirois \& Dodson 2000, Cotano \& Alvarez 2003, Takasuka et al. 2003, 2004). The concept that larger or faster-growing larvae are more likely to survive has been widely accepted (Houde 1987, Anderson 1988, Bailey \& Houde 1989), even though some studies showed that larger larvae were more vulnerable to mortality due to predation (Fuiman 1989, Litvak \& Leggett 1992, Gleason \& Bengston 1996). Growth rate operates as an important determinant for survival during the relatively long duration ( $>40 \mathrm{~d}$ ) of the early life stages of fish species that have a longer planktonic stage in early life, such as gadoid and clupeoid fishes (Campana 1996, Meekan \& Fortier 1996, Butler \& Nishimoto 1997, Takahashi \& Watanabe 2004). In contrast, in fish species such as scombrids and tropical fish species that have a short planktonic stage (ca. $10 \mathrm{~d}$; Houde \& Zastrow 1993) due to high larval growth 


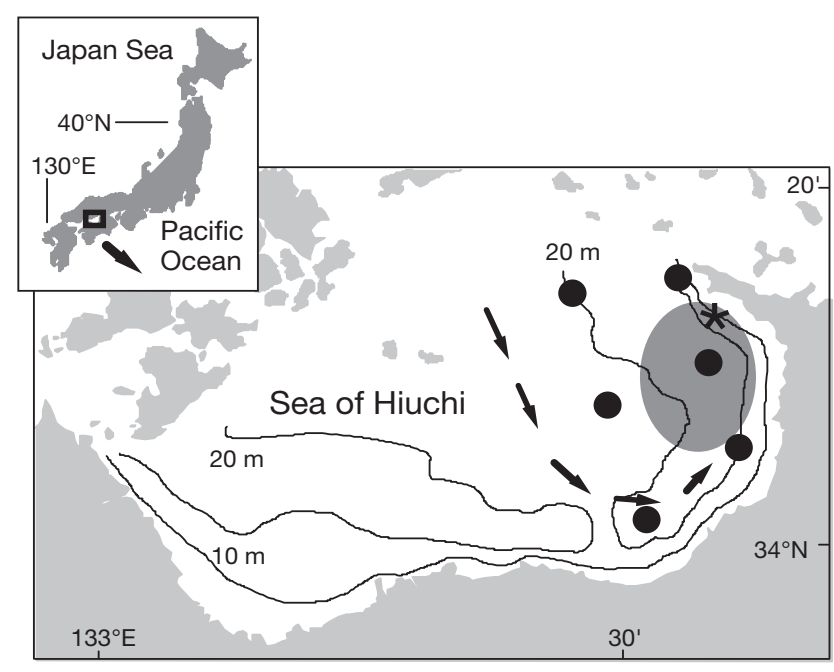

Fig. 1. Scomberomorus niphonius. Sampling area where larvae and juveniles were collected by seine-net (shaded) and 6 stations where monthly surveys for ichthyoplankton prey concentration were conducted in the eastern Sea of Hiuchi $(\bullet)$. Data on daily surface temperature obtained from a buoy $(*)$. Arrows indicate pattern of anti-clockwise residual current

rates, growth-related survival may be detected during the much shorter larval period if a precise analysis is conducted. Growth-related survival mechanisms are expected to operate in different ways (e.g. different timing and duration) among fish species, reflecting the features of early survival strategy of each fish species (Takasuka et al. 2004).

Early life histories of scombrid fishes are characterized by the short duration of the larval period due to fast growth promoted by an early diet shift to larger prey organisms (Hunter 1981). Among scombrids, particularly high growth (>1.0 $\mathrm{mm} \mathrm{d}^{-1}$; DeVries et al. 1990, Shoji \& Tanaka 2005a) and mortality rates $\left(>0.6 \mathrm{~d}^{-1}\right.$ : Grimes \& Kingsford 1996; $>0.7 \mathrm{~d}^{-1}$ : Shoji \& Tanaka 2005b) have been reported in Scomberomorus spp. larvae that are almost exclusively piscivorous from the first feeding (Jenkins et al. 1984, Finucane et al. 1990, Shoji \& Tanaka 2001). Scomberomorus spp. larvae initiate exogenous feeding 3 to $6 \mathrm{~d}$ after hatching (Fukunaga et al. 1982, DeVries et al. 1990), and their larval stage duration is the shortest ( $9 \mathrm{~d}$ ) among teleost larvae (average $33.1 \mathrm{~d}$; Houde \& Zastrow 1993). In contrast, Scomberomorus spp. larvae are highly susceptible to starvation since they need to actively swim with a high metabolic rate to search for and capture fish prey (Margulies 1993, Shoji et al. 2005). High sensitivities to fluctuations in feeding condition makes growth rates of Scomberomorus spp. larvae highly variable (0.2 to $1.3 \mathrm{~mm} \mathrm{~d}^{-1}$ ) from the first feeding stage (Fukunaga et al. 1982, Shoji et al. 2002).

In a manner similar to other scombrid fish larvae such as tuna and related species, Scomberomorus spp. larvae are sparsely distributed in open and oceanic waters so that they are hardly sampled at a high abundance (Collins \& Stender 1987, DeVries et al. 1990, Govoni et al. 2003). These characteristics of the larval distribution pattern have contributed to major difficulties in the improvement of analysis of larval growth and cohort dynamics in Scomberomorus spp. fish. An exception is the Japanese Spanish mackerel Scomberomorus niphonius, which is more estuarinedependent and inhabits the Seto Inland Sea throughout early life stages. Spawning migration from the oceanic waters into the Sea of Hiuchi, central Seto Inland Sea (Fig. 1), occurs in May (Kishida \& Aida 1989), and the larvae and juveniles are abundant from May through to July (Kishida 1988). Young-of-the-year Japanese Spanish mackerel inhabit the Sea of Hiuchi until December, then migrate to oceanic waters (Kishida 1989). In previous studies, no significant relationship was observed between larval $(<12 \mathrm{~mm})$ and juvenile (>12 $\mathrm{mm}$ ) abundance, whereas juvenile abundance was positively correlated with 1 yr old fish abundance in subsequent years in the 1980s (Kishida 1991) and 1990s (Shoji \& Tanaka 2003). Strong year-classes occurred in years when larval growth rate was significantly high (Shoji \& Tanaka 2003). Year-to-year fluctuation in mortality during the larval stage seems to be relatively large, but that between the juvenile and $1 \mathrm{yr}$ old stage is small. In addition, variability in growth during the short larval period is likely to affect the recruitment abundance (abundance of $1 \mathrm{yr}$ old fish) of the Japanese Spanish mackerel.

The objective of the present study was to demonstrate the extent of linkage between growth and survival during the post first-feeding period in Japanese Spanish mackerel. Larvae and juveniles were repeatedly collected in the Seto Inland Sea in June and July from 1997 to 1999. Growth trajectory back-calculated using otolith microanalysis was compared between survivors captured in July and the presumed original population captured in June. Intensity of selection for fast-growing larvae was compared among the 3 years in relation to temperature and ichthyoplankton prey concentration. Rearing experiments were conducted to determine the effect of timing and length of short-term food shortage on growth of the post first-feeding larvae.

\section{MATERIALS AND METHODS}

Field sampling. The Sea of Hiuchi (Fig. 1), central Seto Inland Sea, with an average depth of approximately $17.8 \mathrm{~m}$, is the most enclosed area in the Seto Inland Sea. There is a slow $\left(<5 \mathrm{~cm} \mathrm{~s}^{-1}\right)$, anti-clockwise residual current in the eastern part of the Sea of Hiuchi 
(Yanagi \& Higuchi 1979), and pelagic eggs and larvae are retained inside the current (Kuroda 1993). Larvae of Japanese Spanish mackerel Scomberomorus niphonius and juveniles were collected by seine net in the eastern part of the Sea of Hiuchi in June and July from 1997 to 1999 (27 and 30 June and 12 and 14 July 1997, 27 and 29 June and 10 and 13 July 1998, and 28 and 30 June and 12 and 15 July 1999). The net (approximately $200 \mathrm{~m}$ in length and with a cod end of $2.0 \mathrm{~mm}$ mesh aperture) has been shown to effectively sample young fish and their predators (Takasuka et al. 2003, 2004) and was towed by 2 fishing boats at a ship velocity of 3 to 4 knots during daylight hours (06:00 to 17:00 h). Japanese Larvae and juveniles of Spanish mackerel were sampled from the catch by the net and were preserved in $90 \%$ ethanol.

In order to establish otolith radius-fish length relationship throughout the larval and juvenile stages, larvae of Japanese Spanish mackerel $<10 \mathrm{~mm}$ standard length (SL) were collected using a conical larvae-net with a $1.3 \mathrm{~m}$ mouth diameter and $0.5 \mathrm{~mm}$ mesh aperture in the Sea of Hiuchi in June from 1997 to 1999 (Shoji \& Tanaka 2003). Ichthyoplankton samples collected by the larvae-net were preserved in $90 \%$ ethanol, and 15 larvae $<10 \mathrm{~mm}$ were processed only for the analysis of otolith radius-fish length relationships and coefficient of variance of fish body length (not for growth back-calculation). Live SL $\left(L_{1}\right)$ of larvae and juveniles were calculated using the previously obtained equation between live $L_{1}$ and SL after ethanol preservation $\left(L_{\mathrm{p}}\right): L_{\mathrm{l}}=1.082 \times L_{\mathrm{p}}-0.440\left(\mathrm{n}=260, \mathrm{r}^{2}=\right.$ 0.99; Shoji \& Tanaka 2004)

Otolith processing and growth back-calculation. Larvae and juveniles of Japanese Spanish mackerel ( $\mathrm{n}=$ 505: 460 and 45 fish from the seine net and conical larvae-net samples, respectively) were measured in body length to the nearest $0.1 \mathrm{~mm}$ using a micrometer in the laboratory. Right sagittal otoliths were dissected from larvae and juveniles under a dissecting microscope and mounted on a glass slide with epoxy resin. Daily rings of otoliths were counted and the radius of each ring from the otolith nucleus was measured using a light microscope connected to a video monitor. A measurement transect was set from the nucleus along the maximum radius. All intersections of the daily rings along the transect to the otolith margin were recorded. The total number of daily rings, the radius of each ring and the distance from the nucleus to the margin were recorded.

Hatching date distributions ranged from 3 to 29 June for the larvae and juveniles captured by the seine net. We assumed that larval and juvenile Japanese Spanish mackerel were retained in the eastern Sea of Hiuchi (Kuroda 1993) for about 2 wk between the samplings in June and July, and thus that the fish hatching during
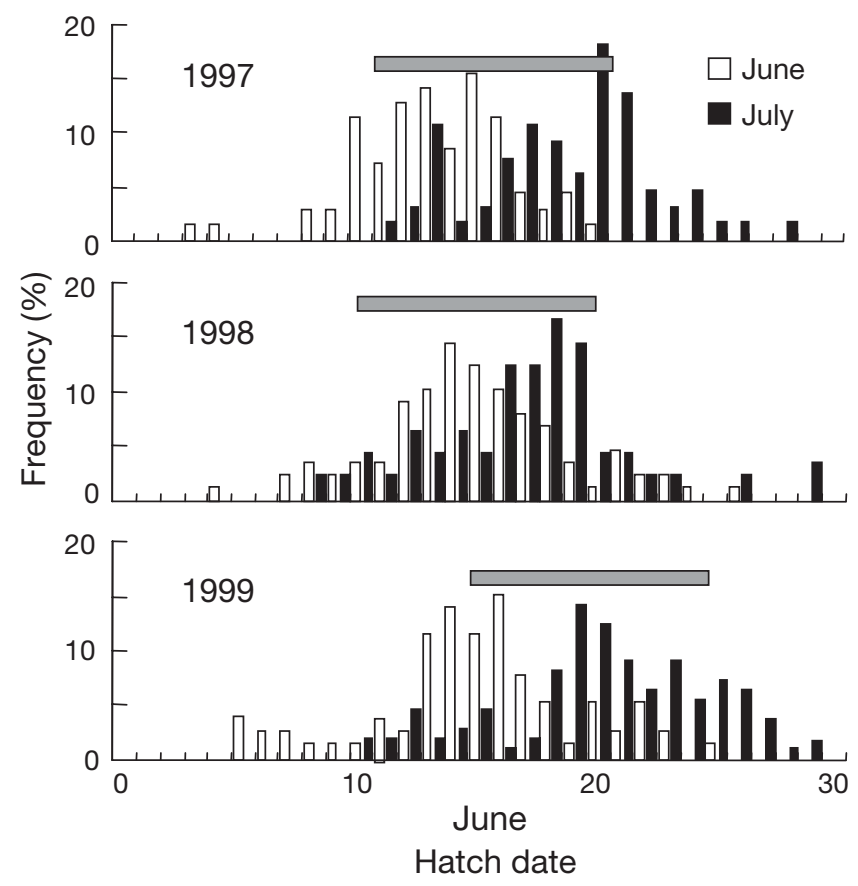

Fig. 2. Scomberomorus niphonius. Hatching date distributions of larvae and juveniles by month of capture (June and July). Fish within a common range of hatching dates (13 to 22 June 1997; 12 to 21 June 1998; 15 to 24 June 1999: indicated by gray horizontal bars) were designated as survivors $\left(\mathrm{SV}_{\text {; }}\right.$ collected in July) and original population (OP; collected in June)

the same period originated from the same hatchingdate cohort. Only fish that hatched within a $10 \mathrm{~d}$ period in each year were used for the growth analysis to ensure that comparisons between month of capture (June vs. July; Fig. 2, Table 1) within year were made with fish originating from the same hatching-date cohort. Accordingly, Japanese Spanish mackerel hatching from 13 to 22 June 1997, from 12 to 21 June 1998, and from 15 to 14 June 1999 and captured in July in each year were regarded as individuals that had survived $\sim 2$ wk longer than larvae hatched during the same period and captured in June. The former individuals were designated as survivors (SV), and the latter as larvae from the original population (OP).

Plots of $L_{\mathrm{l}}$ against maximum otolith radius $\left(R_{\mathrm{m}}\right)$ were expressed by an allometric formula (see 'Results'). Allometric parameters were determined for each fish using the biological intercept method (Campana 1990, Campana \& Jones 1992, Watanabe \& Kuroki 1997). Otolith daily rings start to be deposited at the first feeding stage (Day 5 at $19^{\circ} \mathrm{C}$ ) in Japanese Spanish mackerel (Shoji \& Tanaka 2004). The $L_{1}$ of first feeding larvae was fixed at $5.66 \mathrm{~mm}$ (see 'Results') for the biological intercept. Allometric parameters $a$ and $b$ were calculated for each fish by solving the equations: 
Table 1. Scomberomorus niphonius. Date of capture, hatching date range, sample size (N), age and body length range of larvae and juveniles used for back-calculation of growth. OP: original population; SV: survivors

\begin{tabular}{|cccccrr|}
\hline \multirow{2}{*}{ Year } & Sample & Date of capture & Hatching date & N & Age (d) & Body length (mm) \\
\hline \multirow{2}{*}{1997} & OP & 27 \& 30 Jun & 13-22 Jun & 58 & $8-17$ & $7.5-17.4$ \\
& SV & 12 \& 14 Jul & 13-22 Jun & 47 & $20-31$ & $17.6-31.9$ \\
\multirow{2}{*}{1999} & OP & 27 \& 29 Jun & 12-21 Jun & 72 & $7-17$ & $7.6-16.5$ \\
& SV & 10 \& 13 Jul & 12-21 Jun & 40 & $19-31$ & $16.3-32.4$ \\
& OP & 28 \& 30 Jun & 15-24 Jun & 62 & $6-15$ & $7.5-16.8$ \\
\hline
\end{tabular}

$$
L_{\mathrm{ff}}=a \times R_{\mathrm{ff}}^{b} \text { and } L_{\text {catch }}=a \times R_{\mathrm{catch}^{b}}
$$

where $L_{\mathrm{ff}}$ is SL at first feeding (5.66 mm: see 'Results'), $R_{\mathrm{ff}}$ is the measured $R$ of the first daily ring, $L_{\text {catch }}$ is the $L_{1}$ at catch, and $R_{\text {catch }}$ is the measured $R_{\mathrm{m}} . L_{1}$ at age was back-calculated for each fish. Mean $( \pm \mathrm{SD})$ of the backcalculated $L_{1}$ at Days 10 and 15 and growth rate between Days 5 and $10\left(G_{5-10}\right)$ and Days 10 and 15 (for SV only: $\left.G_{5-10}\right)$ were compared between the 2 sample groups (OP and SV) and among the 3 years within each sample group.

Survival ratio during the post first-feeding period. The intensity of growth-selective survival during the post first-feeding period (Days 5 to 10) was quantified by comparing the frequency distributions of growth rates between OP and SV within each year. Survival ratio (SR; Hovenkamp 1992, Meekan \& Fortier 1996) was calculated for each of 10 growth rate classes $\left(0.40-0.49\right.$ to $\left.1.30-1.39 \mathrm{~mm} \mathrm{~d}^{-1}\right)$ in the frequency distributions during the period from 0 to $5 \mathrm{~d}$ after the first feeding, as follows:

$$
\mathrm{SR}=F_{1} \times F_{\mathrm{S}}^{-1}
$$

where $F_{1}$ and $F_{\mathrm{S}}$ are frequencies of the growth class in the frequency distribution for the large and small group, respectively. Values $>1$ and $<1$ indicate better and worse than average survival for individuals of each growth class, respectively.

Temperature and prey concentration. Daily surface temperatures observed by the buoy in the eastern Sea of Hiuchi (Fig. 1) from April until August from 1997 to 1999 (Kagawa Prefecture Fisheries Experimental Station 1999, 2000, 2001) were used to calculate mean monthly temperature. Concentration of clupeiform larvae, the major prey of Japanese Spanish mackerel larvae and juveniles (Shoji \& Tanaka 2005a), in the eastern part of the Sea of Hiuchi was used as an index of prey abundance. Ichthyoplankton was collected with a conical plankton-net at 6 stations (Fig. 1) on 16 April, 14 May, 4 June, 9 July, and 5 August 1997; 16 April, 13 May, 10 June, 8 July, and 5 August 1998; and 7 April, 12 May, 9 June, 7 July and 11 August 1999. The depth at the 6 stations ranged between 22 and $31 \mathrm{~m}$. The plankton-net, equipped with a flowmeter, was $0.45 \mathrm{~m}$ in diameter and $0.7 \mathrm{~m}$ in length with a mesh aperture of $0.33 \mathrm{~mm}$, and was towed vertically at $1.0 \mathrm{~m} \mathrm{~s}^{-1}$ from $1 \mathrm{~m}$ above the sea bottom to the surface. Prey concentration was expressed as the number of clupeiform larvae $\mathrm{m}^{-3}$. These data originated from the monthly survey by Ehime Prefecture Fisheries Experimental Station (1999, 2000, 2001).

Feeding experiments in the laboratory. Artificial fertilizations were carried out with a pair of adult Japanese Spanish mackerel captured using a drift gill net in the Sea of Harima, eastern Seto Inland Sea, in May 2001. Approximately 10000 fertilized eggs were transported to the Maizuru Fisheries Research Station, Field Science, Education and Research Center, Kyoto University, and were maintained in three $500 \mathrm{l}$ tanks with filtered seawater under natural light conditions. Water temperature was maintained at $19.6 \pm 0.4^{\circ} \mathrm{C}$. Yolk-sac red sea bream Pagrus major larvae were fed at a density of 100 ind. $\mathrm{l}^{-1}$. Ten Japanese Spanish mackerel larvae were sampled from the tank every day (30 fish only on the day of the first feeding) and $L_{1}$ was measured.

The effect of delayed initial feeding and short-term starvation on larval growth up to Day 10 was examined by establishing 2 feeding regimes: (1) fed with red sea bream larvae and (2) no prey. Because Japanese Spanish mackerel larvae are piscivorous and will readily cannibalize siblings under conditions of no-prey supply (Shoji \& Tanaka 2001), each larva (10 to 20, depending on the experimental day) was individually kept in a 21 tank under no-prey supply. The following feeding conditions were simulated: (1) high prey levels (larvae could feed) followed by low prey levels (larvae could not feed) for $1 \mathrm{~d}$ from Days 5 to 9, then reintroduction of high prey levels; (2) high prey levels, then introduction of low prey levels (for a maximum of $3 \mathrm{~d}$ ). Under Condition 2, larvae were sampled after $3 \mathrm{~d}$ starvation because first-feeding Japanese Spanish mackerel larvae do not survive $4 \mathrm{~d}$ under starved conditions (Shoji et al. 2002). A total of 10 different feeding regimes (including a control group: fed continuously) were set; 4 to 10 replicates were made for each treat- 
ment. At the end of each experiment, fish were sampled and $L_{1}$ was measured. Mean growth rate during experiments $\left(G_{\mathrm{e}}\right)$ was estimated for each larva following the equation:

$$
G_{\mathrm{e}}=\left(L_{\mathrm{s}}-L_{\mathrm{f}}\right) \times(D-5)^{-1}
$$

where $L_{\mathrm{s}}$ is measured $L_{\mathrm{l}}$ at sampling, $L_{\mathrm{f}}$ is SL at first feeding (5.66 mm; see 'Results'), and $D$ is age (d) at sampling.

\section{RESULTS}

\section{Back-calculated growth}

Plots of $L_{1}(\mathrm{~mm})$ on $R_{\mathrm{m}}(\mu \mathrm{m})$ for the larval and juvenile Japanese Spanish mackerel were expressed by allometric relationship as follows (Fig. 3):

$$
\begin{aligned}
& \text { 1997: } L_{\mathrm{l}}=0.698 \times R_{\mathrm{m}}{ }^{0.615}\left(\mathrm{n}=191, \mathrm{r}^{2}=0.968\right) \\
& \text { 1998: } L_{\mathrm{l}}=0.659 \times R_{\mathrm{m}}{ }^{0.628}\left(\mathrm{n}=132, \mathrm{r}^{2}=0.975\right) \\
& \text { 1999: } L_{\mathrm{l}}=0.663 \times R_{\mathrm{m}}{ }^{0.631}\left(\mathrm{n}=187, \mathrm{r}^{2}=0.968\right)
\end{aligned}
$$

We assumed that the sagittal otolith growth relative to larval and juvenile growth could be expressed by allometric equation, and determined the allometric parameters for individual fish to back-calculate the

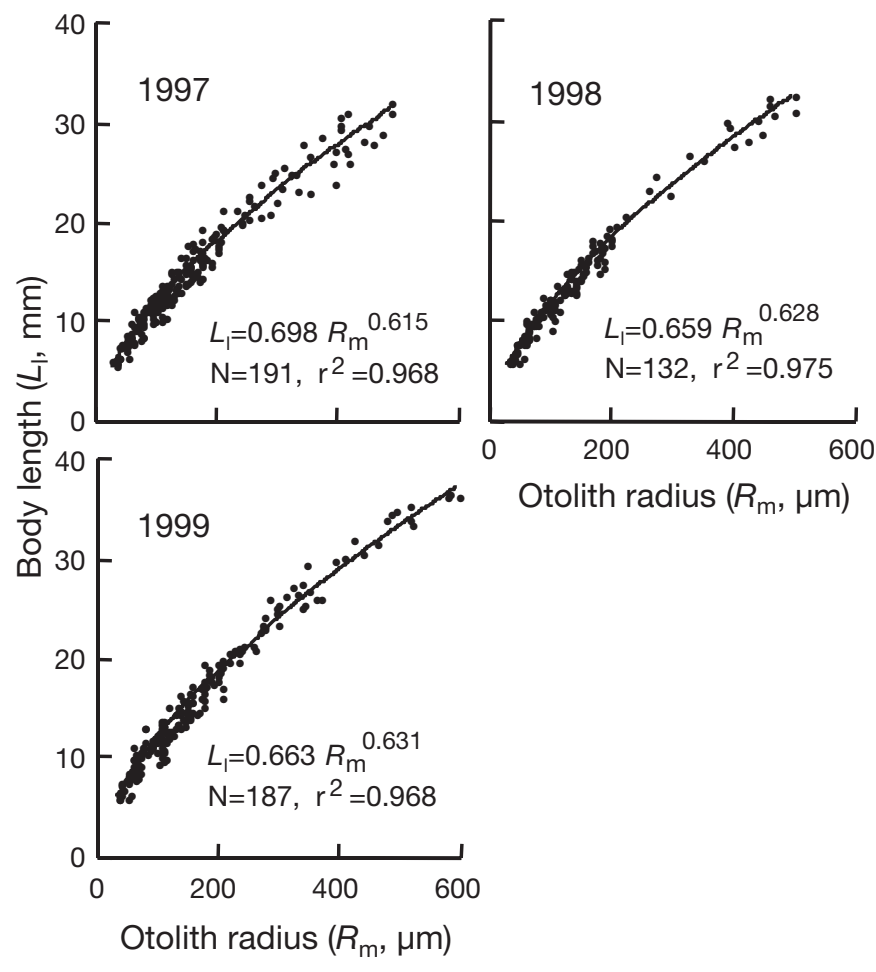

Fig. 3. Scomberomorus niphonius. Relationships between lar$\mathrm{val}$ and juvenile otolith radius $\left(R_{\mathrm{m}}\right)$ and body length $\left(L_{1}\right)$ from 1997 to 1999. Data from larvae $<10 \mathrm{~mm}$ (15 ind. $\mathrm{yr}^{-1}$ ) included to construct allometric formula

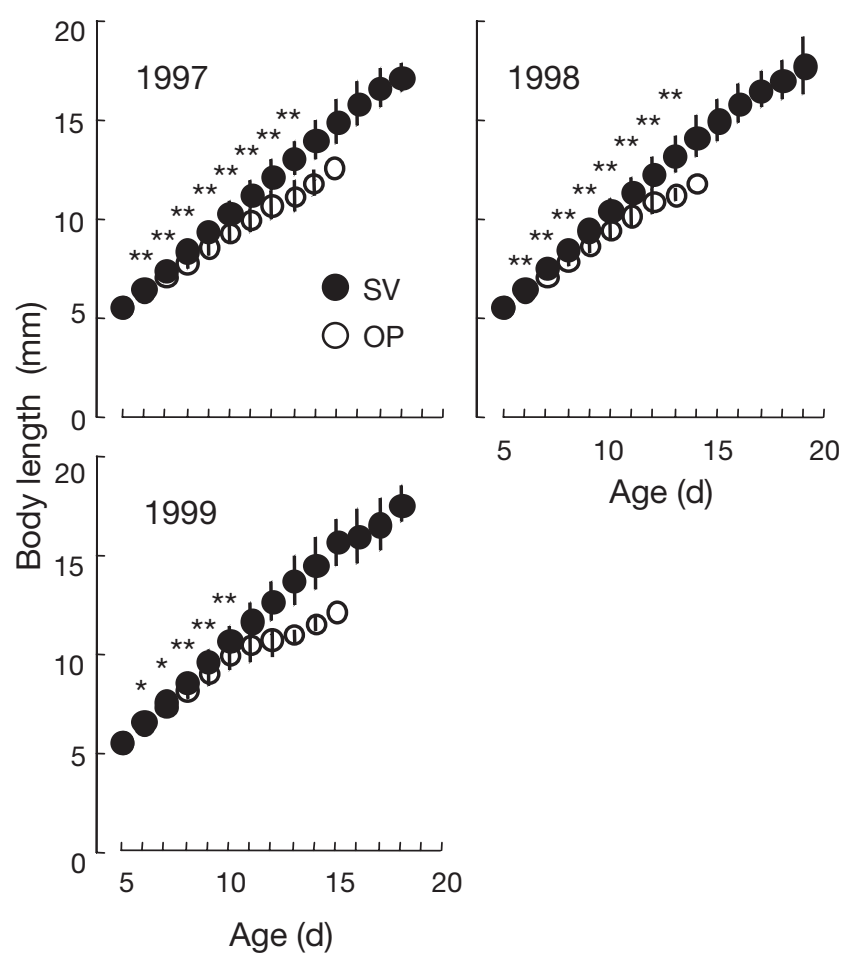

Fig. 4. Scomberomorus niphonius. Back-calculated mean $( \pm$ SD) body length at ages of Japanese Spanish mackerel larvae and juveniles. OP collected in June, SV collected in July. Significant differences between size groups indicated as ${ }^{*} \mathrm{p}<0.001 ;{ }^{*} \mathrm{p}<0.0001$ ( $t$-test)

size-at-age of each fish as described in 'Materials and methods'.

The mean back-calculated $L_{1} \mathrm{~S}$ of the SV were significantly larger than those of the OP at Days 6 to 13 in 1997 and 1998 ( $t$-test, $\mathrm{p}<0.0001$ ), and at Days 6 and 7 $(t$-test, $\mathrm{p}<0.001)$ and Days 8 to 10 in 1999 ( $t$-test, $\mathrm{p}<$ 0.0001) when compared within a year (Fig. 4). There was also an effect of year on the mean back-calculated $L_{\mathrm{l}} \mathrm{S}$. Among the OPs, mean $L_{\mathrm{l}}$ on Day 10 in 1999 $(10.01 \pm 0.75 \mathrm{~mm})$ was significantly larger than those in 1997 (9.40 $\pm 0.54 \mathrm{~mm}$; ANOVA followed by Tukey's test, $\mathrm{p}<0.001)$ and in 1998 (9.50 $0.51 \mathrm{~mm}, \mathrm{p}<0.01)$. Among the SVs, mean $L_{1} S$ on Day 10 in 1999 (10.71 \pm $0.69 \mathrm{~mm}$ ) was significantly larger than that in 1997 $(10.31 \pm 0.51 \mathrm{~mm}, \mathrm{p}<0.01)$ but not that in $1998(10.46 \pm$ $0.56 \mathrm{~mm}, \mathrm{p}>0.05)$, and that on Day 15 in 1999 (15.79 \pm $1.27 \mathrm{~mm}$ ) was significantly larger than those in 1997 (15.02 $\pm 1.03, \mathrm{p}<0.01)$ and $1998(15.07 \pm 0.96, \mathrm{p}<0.05)$.

The effects of group (OP or SV) and year on the back-calculated growth rate were also significant (Fig. 5). Mean growth rate $5 \mathrm{~d}$ after the first feeding $\left(G_{5-10}\right)$ of the OP was significantly lower than that of the $\mathrm{SV}$ in each year $(t$-test, $\mathrm{p}<0.0001)$. Mean growth rate during each $5 \mathrm{~d}$ period $\left(G_{5-10}\right.$ and $\left.G_{10-15}\right)$ of the OP and SV in 1999 was significantly higher than in either 
Table 2. Scomberomorus niphonius. Relative frequencies of back-calculated growth rate classes of OP and SV, and survival ratios (SR) of larvae and juveniles in the eastern Sea of Hiuchi from 1997 to 1999. SR = 0 when the class of growth rate is not represented in the SV. ?: growth class is not represented in OP; -: growth class is represented neither in OP nor SV

\begin{tabular}{|c|c|c|c|c|c|c|c|c|c|}
\hline \multirow{2}{*}{$\begin{array}{l}\text { Growth class } \\
\left(\mathrm{mm} \mathrm{d}^{-1}\right)\end{array}$} & \multicolumn{3}{|c|}{$-1997-$} & \multicolumn{3}{|c|}{$1998-$} & \multirow[b]{2}{*}{ OP } & \multirow{2}{*}{$\begin{array}{c}1999 \\
\text { SV }\end{array}$} & \multirow[b]{2}{*}{ SR } \\
\hline & $\mathrm{OP}$ & SV & SR & $\mathrm{OP}$ & SV & SR & & & \\
\hline $0.40-0.49$ & 3.4 & 0 & 0 & 0 & 0 & - & 0 & 0 & - \\
\hline $0.50-0.59$ & 3.4 & 0 & 0 & 2.8 & 0 & 0 & 0 & 0 & - \\
\hline $0.60-0.69$ & 22.4 & 0 & 0 & 19.4 & 0 & 0 & 16.1 & 1.4 & 0.09 \\
\hline $0.70-0.79$ & 36.2 & 8.5 & 0.23 & 33.3 & 2.5 & 0.08 & 9.7 & 5.8 & 0.60 \\
\hline $0.80-0.89$ & 25.9 & 27.7 & 1.07 & 33.3 & 25.0 & 0.75 & 19.4 & 10.1 & 0.52 \\
\hline $0.90-0.99$ & 8.6 & 31.9 & 3.70 & 8.3 & 35.0 & 4.20 & 27.4 & 23.2 & 0.85 \\
\hline $1.00-1.09$ & 0 & 17.0 & $?$ & 2.8 & 20.0 & 7.20 & 24.2 & 30.4 & 1.26 \\
\hline $1.10-1.19$ & 0 & 8.5 & $?$ & 0 & 12.5 & $?$ & 3.2 & 17.4 & 5.39 \\
\hline $1.20-1.29$ & 0 & 6.4 & $?$ & 0 & 2.5 & ? & 0 & 8.7 & $?$ \\
\hline $1.30-1.39$ & 0 & 0 & - & 0 & 2.5 & $?$ & 0 & 2.9 & $?$ \\
\hline
\end{tabular}

of the other 2 years (Kruskal-Wallis test followed by Dunnett's test for multiple comparison, $\mathrm{p}<0.01$ ).

Comparison of frequency distribution of growth rate between the OP and SV within year indicated that faster growing fish survived better during the $5 \mathrm{~d}$ after first feeding (Table 2). More than $98.6 \%$ of the SV had $G_{5-10}>0.7 \mathrm{~mm} \mathrm{~d}^{-1}$ and $91.5 \% G_{5-10}>0.8 \mathrm{~mm} \mathrm{~d}^{-1}$. Fish with $G_{5-10}<0.8 \mathrm{~mm} \mathrm{~d}^{-1}$ showed survival ratios $<1$ in all years. In $1999,>70 \%$ of the OP grew at a $G_{5-10}$ $>0.8 \mathrm{~mm} \mathrm{~d}^{-1}$.

Coefficient of variation (CV) of $L_{\text {catch }}$ was calculated for Japanese Spanish mackerel at 5 to $34 \mathrm{~d}$ (data from 3 yr combined). The CV was high during the post first-

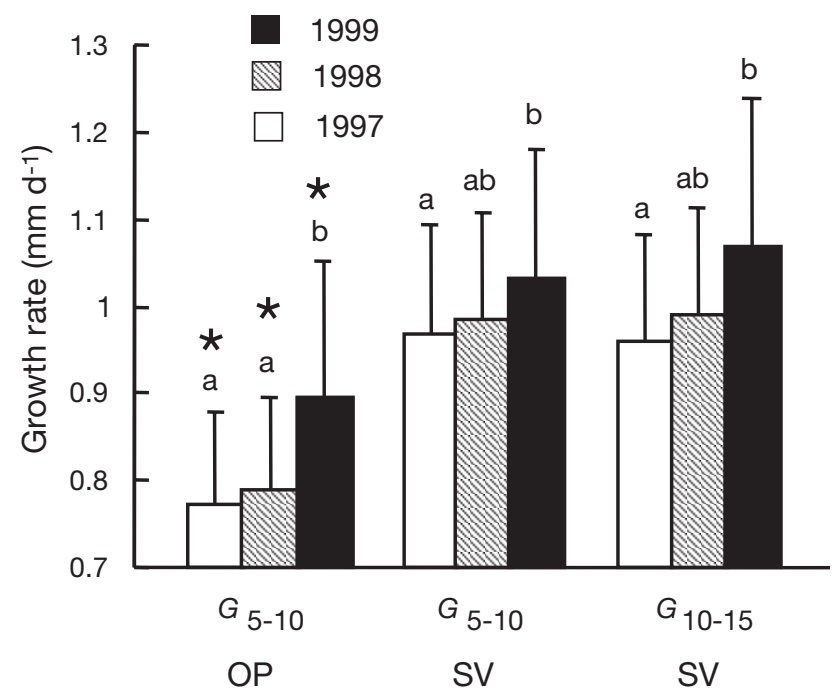

Fig. 5. Scomberomorus niphonius. Back-calculated larval growth rate by age interval (Days 5 to 10 : $G_{5-10}$ i Days 10 to 15 : $\left.G_{10-15}\right)$ from 1997 to 1999 . OP collected in June, SV collected in July. *: significant difference in $G_{5-10}$ between OP and SV within year $(t$-test, $\mathrm{p}<0.0001)$. Different alphabetical characters indicate significant differences (Kruskal-Wallis test followed by Dunnett's test for multiple comparison, $\mathrm{p}<0.01$ ) among years within a given group (OP or SV) and age interval $\left(G_{5-10}\right.$ or $\left.G_{10-15}\right)$ feeding period, Days 6 to 10, ranging higher than 0.15 before decreasing to 0.06 on Day 12. The CV was continuously $<0.15$ thereafter (Fig. 6).

\section{Temperature and ichthyoplankton prey abundance}

Among the 3 years, mean temperature was lowest in April, May, July and August 1999. Year had a significant effect on temperature in these months (Fig. 7). In June, mean temperature ranged between $21.6^{\circ} \mathrm{C}$ (1997) and $22.2^{\circ} \mathrm{C}$ (1999). At the 6 stations, mean prey concentration between May and August was highest in 1999 among the 3 years (Fig. 7). There was a significant effect of year on concentration from June to August (Kruskal-Wallis test followed by Dunnett's test for multiple comparison, $\mathrm{p}<0.05$ ).

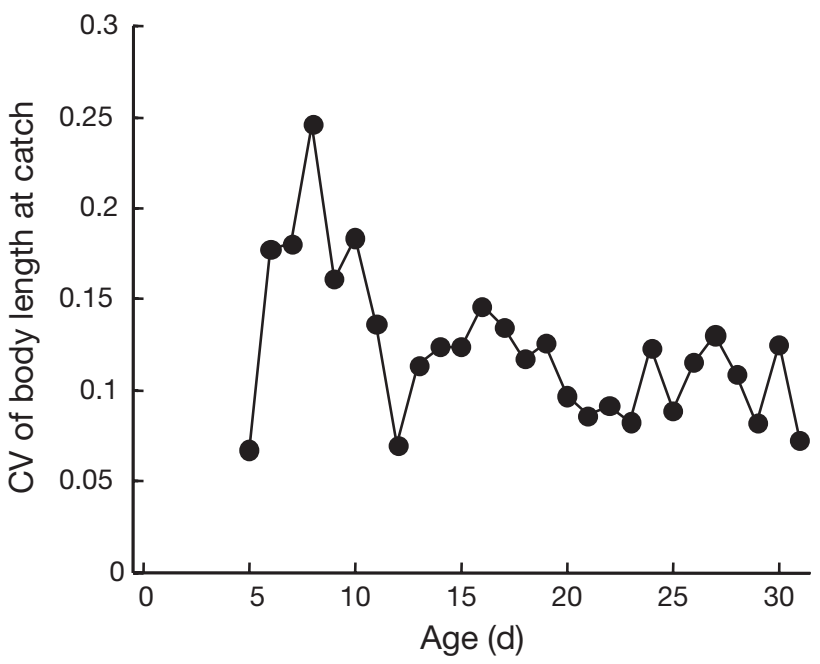

Fig. 6. Scomberomorus niphonius. Coefficient of variation (CV) of larval and juvenile body length at catch by age. Data from 3 years (1997 to 1999) were pooled. Each data point consists of $>8$ individuals 

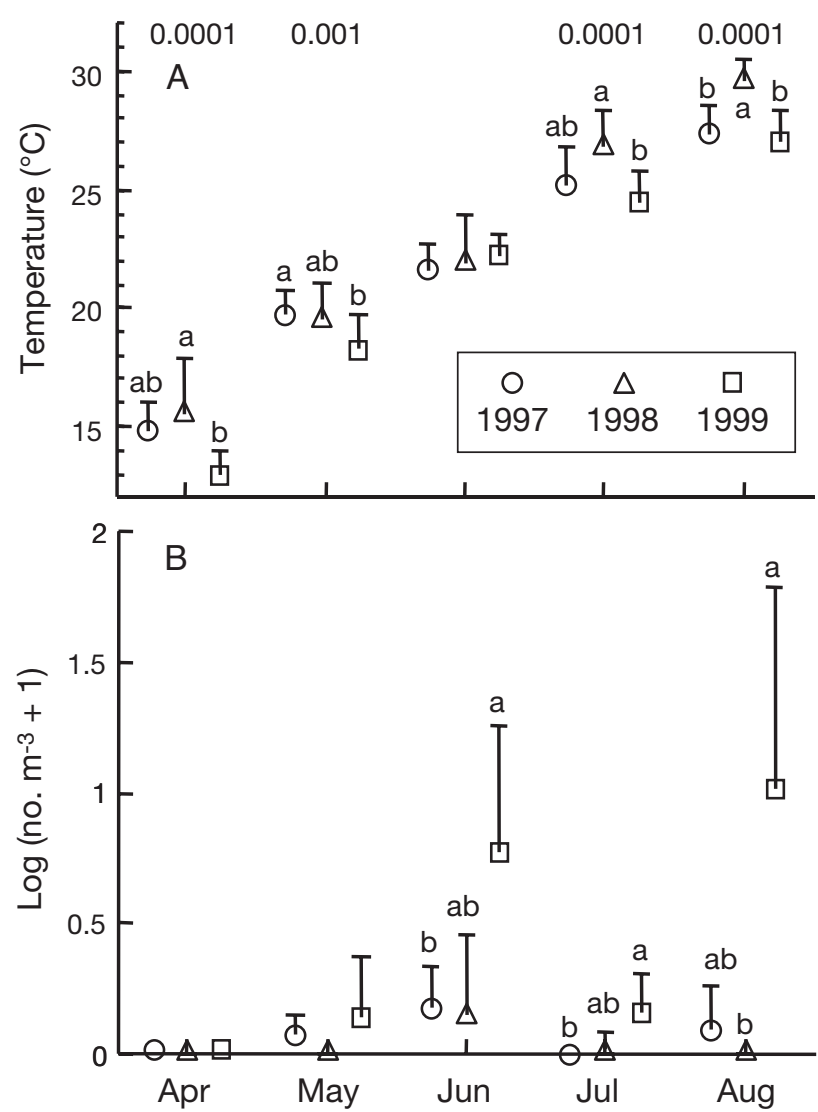

Fig. 7. (A) Seasonal changes in mean monthly temperature observed at the buoy and (B) concentration of ichthyoplankton prey (clupeiform larvae) at 6 stations in the eastern Sea of Hiuchi from April to August, 1997 to 1999. Prey concentration expressed as $\log$ (no. of ind. $\mathrm{m}^{-3}+1$ ). Vertical bars indicate $\mathrm{SD}$; different letters above bars indicate significant difference among years within month (A: ANOVA followed by Tukey's test for multiple comparison, alpha level indicated for each month; B: Kruskal-Wallis test followed by Dunnett's test for multiple comparison, all $\mathrm{p}<0.05$ )

\section{Effect of short-term starvation on larval growth}

Variability in $L_{1}$ among the feeding regimes under laboratory conditions became clear during the post first-feeding stage (Fig. 8). Mean $L_{1}$ of larvae was $5.66 \mathrm{~mm}$ at first feeding (Day 5). The continuously fed group reached $9.45 \mathrm{~mm}$ on Day 10. Increase in larval $L_{1}$ was negligible during periods of no-prey supply. Difference in $L_{1}$ between the continuously fed group and groups subjected to the no-prey condition between Days 5 and 6 was significant on Days 8 and 9, respectively (Mann-Whitney's $U$-test, $\mathrm{p}<0.0001$ ). There were significant differences in $L_{1}$ on Day 10 among the 8 feeding regimes (Kruskal-Wallis test followed by Dunnett's test for multiple comparison, $\mathrm{p}<$ 0.05).
The $G_{\mathrm{e}}\left(\mathrm{mm} \mathrm{d}^{-1}\right)$ ranged between $0.08( \pm 0.07)$ in the group subjected to the no-prey condition between Days 5 and 8 and $0.76( \pm 0.10)$ in the continuously fed group (Fig. 9). The effect of timing of the $1 \mathrm{~d}$ no-prey period on growth was significant (Kruskal-Wallis test, $\mathrm{p}<0.02$ ), even though the duration of the no-prey period was equal among the 5 treatments (all for $1 \mathrm{~d}$, initiated between Days 5 and 10). A decrease in mean larval growth rate was more evident in groups that experienced an earlier $1 \mathrm{~d}$ period of no-prey supply.

\section{DISCUSSION}

\section{Comparison of original population and survivors}

The intensity of phenotypic selection for fast growth can be investigated by comparing the frequency distribution of growth rates of 2 groups of fish during different growth intervals (Hovenkamp 1992, Meekan \& Fortier 1996, Takasuka et al. 2004). This approach requires the assumption that the same cohort of young fish is repeatedly sampled. We assumed that Japanese

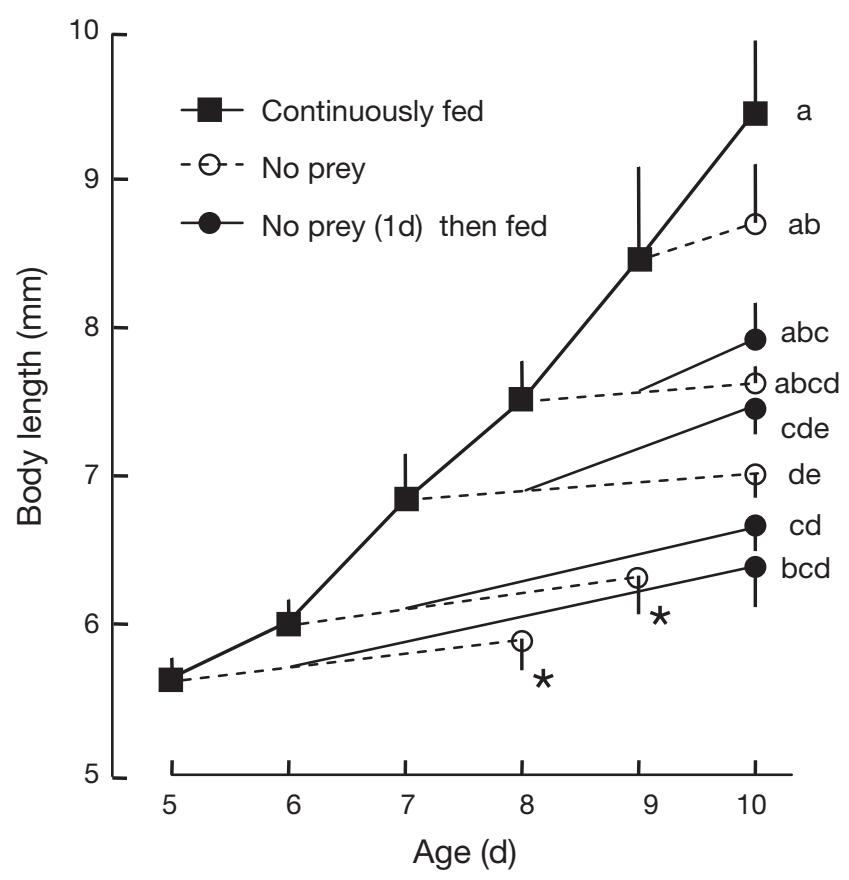

Fig. 8. Scomberomorus niphonius. Growth of larvae under different laboratory feeding conditions. Symbols indicate mean body length, vertical bars indicate SD. Different letters indicate significant difference in larval body length on Day 10 among treatments (Kruskal-Wallis test followed by Dunnett's test for multiple comparison, $p<0.05)$. *: significant differences on Day $8(p=0.0011)$ and Day $9(p<0.0001)$ between the continuously fed group and the group subjected to the no prey (1 d) then fed condition 


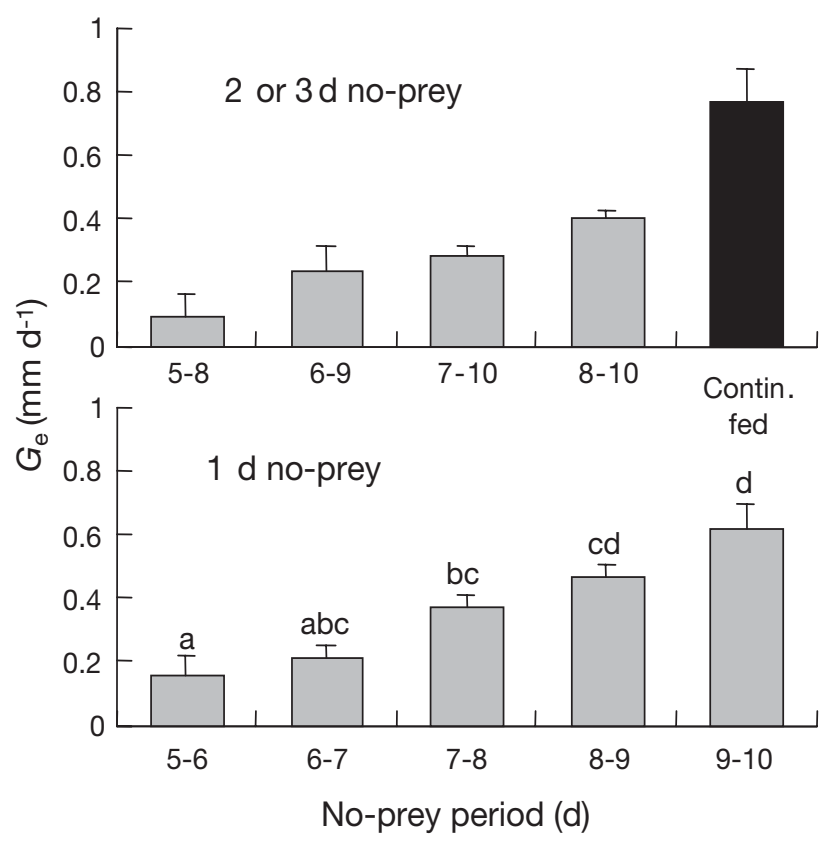

Fig. 9. Scomberomorus niphonius. Mean growth rate during $5 \mathrm{~d}$ subsequent to first feeding (Days 5 to 10 ) of larvae $\left(G_{\mathrm{e}}\right)$ under different laboratory feeding conditions. (A) $G_{\mathrm{e}}$ of continuously fed group (black bar) shown for comparison. (B) Effect of timing of the $1 \mathrm{~d}$ no-prey condition on growth rate was significant; different letters above bars indicate significant differences among treatments (Kruskal-Wallis test followed by Dunnett's test for multiple comparison: $\mathrm{p}<0.02$ )

Spanish mackerel larvae and juveniles were retained in the eastern part of the Sea of Hiuchi, and that the OP and SV originated from the same hatch-date cohort. Japanese Spanish mackerel that hatched in the eastern part of the Sea of Hiuchi, together with other ichthyoplankton, can be passively retained in the anticlockwise residual current throughout the larval and early juvenile periods (Yanagi \& Higuchi 1979). Japanese anchovy Engraulis japonicus larvae, the major prey item of larval and juvenile Japanese Spanish mackerel, are most abundant in the anti-clockwise residual current in the eastern part of the Sea of Hiuchi (Kuroda 1993). In Japanese Spanish mackerel, fin rays develop at $12 \mathrm{~mm}$ (Kishida 1991), which enables the larvae to swim faster and to more effectively capture Japanese anchovy larvae. Therefore, we found no reason for positive emigration of larval and juvenile Japanese Spanish mackerel out of the eastern part of the Sea of Hiuchi where their prey organism is abundant. In the present study, Japanese Spanish mackerel larvae and juveniles that hatched within a $10 \mathrm{~d}$ period in each year were used for growth analysis so that we could compare the sizes-at-age and growth rates during the post firstfeeding period between the OP and SV.

\section{Timing of growth-selective survival and its role in determination of recruitment}

Selection for faster growing individuals was reported at 30 to $40 \mathrm{~mm}$ in total length in yellow perch Perca flavescens (Post \& Prankevicius 1987), at 41 to $80 \mathrm{~d}$ in Atlantic cod Gadus morhua (Meekan \& Fortier 1996), at $45 \mathrm{~d}$ in Pacific hake Merluccius productus (Butler \& Nishimoto 1997), at 1 to 3 mo after settlement in a common damselfish Neopomacentrus filamentosus (Vigliola \& Meekan 2002), and at 40 to $60 \mathrm{~d}$ in Japanese anchovy (Takahashi \& Watanabe 2004). The duration of the phase that is critical in controlling the growthrelated survival and in establishing the year-class strength has been considered to be about $90 \mathrm{~d}$ in Atlantic cod (Campana 1996) and about 1 yr in Japanese sardine Sardinops malanostictus (Watanabe et al. 1995). Takasuka et al. (2004) suggested that the roles of growth-related survival mechanisms in the recruitment dynamics could differ between pelagic fish species that undergo metamorphosis (with a gradual change in morphological, physiological, and ecological aspects) and those that settle through metamorphosis such as flatfishes. Compared to other fish species that have a slower growth rate and longer planktonic period in early life, the selection for fast growing larvae becomes evident at a much earlier stage in Japanese Spanish mackerel (Days 5 to 10: 1 to $5 \mathrm{~d}$ after the first feeding). In addition, growth-selective mortality is likely to play a significant role in recruitment dynamics during a much earlier and/or shorter period of the life history. In the Seto Inland Sea, strong year-classes of Japanese Spanish mackerel occurred in years (1995 and 1999) when the larval growth rate was significantly high due to high ichthyoplankton prey concentrations (Shoji \& Tanaka 2003, present study). Based on our observations, the successful recruitment in 1995 and 1999 may be attributed to the high larval growth rate, which increased the larval survival probability through controlling the growth-selective survival process.

Growth-selective survival would be less evident after the juvenile stage in Japanese Spanish mackerel. Mean growth rate of the early juveniles exceeded $2.0 \mathrm{~mm} \mathrm{~d}^{-1}$ (Fukunaga et al. 1982). The rapid increase in body size and the morphological development during metamorphosis would provide juvenile Japanese Spanish mackerel with faster swimming, and refined mechano-reception and visual/motor abilities enabling them to capture prey, which can make their growth and survival more independent of prey concentration. This assumption would be supported by the decrease in CV of body length after the late larval stage of Japanese Spanish mackerel. 


\section{Significance of high ichthyoplankton prey concentration to attain high growth rates}

Growth analysis demonstrated that the intensity of selection for fast growing Japanese Spanish mackerel varied among the 3 years. The majority of SV had a $G_{5-10}>0.8 \mathrm{~mm} \mathrm{~d}^{-1}$ in all years, showing that larvae with a growth rate $<0.8 \mathrm{~mm} \mathrm{~d}^{-1}$ hardly survived the following $2 \mathrm{wk}$. Variability in the relative contribution of fish with a $G_{5-10}>0.8 \mathrm{~mm} \mathrm{~d}^{-1}$ to total OP $(34.5 \%$ in $1997,44.4 \%$ in 1998 , and $74.2 \%$ in 1999 ) indicates that growth-dependent survival probability of the larvae differed among the 3 years. We conclude that conditions for growth of Japanese Spanish mackerel larvae, i.e. ichthyoplankton prey concentrations, were more suitable in 1999, which provided greater chances of larval survival by promoting their growth rate and making the selection for fast growing individuals less intense. Temperature directly and/or indirectly affects growth of marine fish larvae (Hunter 1981, Houde \& Zastrow 1993). However, results from a whole-bay survey in May 1997 demonstrated that there was no significant correlation between temperature and growth rate of Japanese Spanish mackerel larvae, whereas ichthyoplankton prey concentration was positively correlated with larval growth rate (Shoji \& Tanaka 2004). In the present study, the interannual comparison showed that larval growth rate was significantly higher in 1999, even though there was a minimal difference in June temperature among the 3 years. It is likely that variability in ichthyoplankton prey concentration is one of the most important determinants that affects the larval survival window and recruitment dynamics.

Our present laboratory experiments supported the conclusion that high variability in growth of Japanese Spanish mackerel larvae reflects one of the ecological features of their early survival strategies: high sensitivity to fluctuation in ichthyoplankton prey concentration. Only a single day of starvation led to a significant depression in the growth rate of the post first-feeding larvae. The effect of the $1 \mathrm{~d}$ starvation on larval growth up to Day 10 was more evident when larvae were starved earlier on in this period. Although the larval growth rate might have been under-estimated due to the small tank size used in experiments, short-term starvation during the earlier period seems to more strongly affect the growth of Japanese Spanish mackerel larvae. In addition, retarded larval growth due to short-term starvation was not compensated for even though the larvae were re-fed.

Although data on the relative contribution of starvation-related and other mortalities to total mortality of Japanese Spanish mackerel are not available, fluctuation in prey concentration may drive variability in growth-selective larval mortality because of the high vulnerability to starvation of the larvae. Mortality coefficients of larval Japanese Spanish mackerel estimated from declines in larval abundance at age in the Sea of Hiuchi $\left(0.748\right.$ to $0.821 \mathrm{~d}^{-1}$; Shoji \& Tanaka 2005b) approximate to the values of larval mortality due to starvation (40 to $50 \% \mathrm{~d}^{-1}$ ) estimated by histological analysis in another Scomberomorus species, S. sierra, in waters off Panama (Margulies 1993). Under laboratory conditions, Japanese Spanish mackerel larvae have been reported to die within $4 \mathrm{~d}$ of first feeding under conditions of no-prey supply. The point-of-noreturn of the larvae is $1 \mathrm{~d}$ after first feeding (Shoji et al. 2002). Therefore, starvation itself and starvationinduced predation would greatly contribute to mortality in the post first-feeding period of Japanese Spanish mackerel larvae, whereas predation is generally the most important factor that controls larval mortality in marine fish (Houde 1987, Bailey \& Houde 1989).

Acknowledgements. We sincerely thank Dr. A. Takasuka, National Research Institute of Fisheries Science, for his critical and constructive comments on an earlier draft of the manuscript. Discussions with Dr. Y Yamashita and R. Masuda, Maizuru Fisheries Research Station, Kyoto University, were helpful in the development of the manuscript. Mr. T. Maehara, K. Ito, and staff of the Ehime Prefecture Chuyo Fisheries Experimental Station assisted with field work. Comments by 4 anonymous reviewers significantly improved the manuscript. This study was supported in part by Fellowships of the Japan Society for Promoting Science awarded to J.S.

\section{LITERATURE CITED}

Anderson JT (1988) A review of size-dependent survival during pre-recruit stages of fishes in relation to recruitment. J Northwest Atl Fish Sci 8:55-66

Bailey KM, Houde ED (1989) Predation on eggs and larvae of marine fishes and the recruitment problem. Adv Mar Biol 251-83

Butler JL, Nishimoto RN (1997) Growth and cohort dynamics of larval Pacific hake (Merluccius productus). Calif Coop Ocean Fish Invest Rep 38:63-68

Campana SE (1990) How reliable are growth back-calculations based on otolith? Can J Fish Aquat Sci 47:2219-2227

Campana SE (1996) Year-class strength and growth rate in young Atlantic cod Gadus morhua. Mar Ecol Prog Ser 135: $21-26$

Campana SE, Jones CM (1992) Analysis of otolith microstructure data. Can Spec Publ Fish Aquat Sci 117:73-100

Collins MR, Stender BW (1987) Larval king mackerel (Scomberomorus cavalla), Spanish mackerel (S. maculatus), and bluefish (Pomatomus saltatrix) off the southeast coast of the United States, 1973-1980. Bull Mar Sci 41: 822-834

Cotano U, Alvarez P (2003) Growth of young-of-the-year mackerel in the Bay of Biscay. J Fish Biol 62:1010-1020

DeVries D, Grimes C, Lang K, White B (1990) Age and growth of king and Spanish mackerel larvae and juveniles from the Gulf of Mexico and U.S. South Atlantic Bight. Environ Biol Fish 29:135-143

Ehime Prefecture and Chuyo Fisheries Experimental Stations 
(1999-2001) Results of monthly survey in the shallow waters. Rep Fish Oceanogr Forecast Project. Ehime Prefecture and Chuyo Fisheries Experimental Stations, Ehime

Finucane JH, Grimes CB, Naughton SP (1990) Diets of young king and Spanish mackerel off the southeast United States. Northeast Gulf Sci 11:145-153

Fuiman LA (1989) Vulnerability of Atlantic herring larvae to predation by yearling herring. Mar Ecol Prog Ser 51: 291-299

Fukunaga T, Ishibashi N, Mitsuhashi N (1982) Artificial fertilization and seedling propagation of Spanish mackerel. Saibai Giken 11:29-48

Gleason TR, Bengtson DA (1996) Size-selective mortality of inland silversides: evidence from otolith microstructure. Trans Am Fish Soc 125:860-873

Govoni JJ, Laban EH, Hare JA (2003) The early life history of swordfish (Xiphias gladius) in the western North Atlantic. Fish Bull 101:778-789

Grimes CB, Kingsford MJ (1996) How do riverine plumes of different sizes influence fish larvae: do they enhance recruitment? Mar Freshw Res 47:191-208

Hare JA, Cowen RK (1997) Size, growth, development, and survival of the planktonic larvae of Pomatomus saltatrix (Pisces: Pomatomidae). Ecology 78:2415-2431

Houde ED (1987) Fish early life dynamics and recruitment variability. Am Fish Soc Symp 2:17-29

Houde ED, Zastrow CE (1993) Ecosystem-and taxon-specific dynamic and energetics properties of larval fish assemblages. Bull Mar Sci 53:290-335

Hovenkamp F (1992) Growth-independent mortality of larval plaice Pleuronectes platessa in the North Sea. Mar Ecol Prog Ser 82:95-101

Hunter JR (1981) Feeding ecology and predation of marine fish larvae. In: Lasker R (ed) Marine fish larvae. University of Washington Press, Seattle, p 33-77

Jenkins GP, Milward NE, Harwick RF (1984) Food of larvae of Spanish mackerels, genus Scomberomorus (Telostei: Scombridae), in shelf waters of the Great Barrier Reef. Aust J Mar Freshw Res 35:477-482

Kagawa Prefecture Fisheries Experimental Station (1999-2001) Results from automatic observation on the temperature of the Sea of Hiuchi. Annu Rep Kagawa Prefecture Fisheries Experimental Station, Takamatsu

Kishida T (1988) Vertical and horizontal distribution of eggs and larvae of Japanese Spanish mackerel in the central waters of the Seto Inland Sea. Bull Jpn Soc Sci Fish 54:1-8

Kishida T (1989) Distribution and migration of Japanese Spanish mackerel based on the catch and effort data in the central and western waters of the Seto Inland Sea. Bull Nansei Reg Fish Res Lab 22:13-27

Kishida T (1991) Fluctuations in year-class strength of Japanese Spanish mackerel in the central Seto Inland Sea. Bull Jpn Soc Sci Fish 57:1103-1109

Kishida T, Aida K (1989) Maturation and spawning of Japanese Spanish mackerel in the central and western waters of the Seto Inland Sea. Bull Jpn Soc Sci Fish 55:2065-2074

Kuroda H (1993) Average oceanographic conditions of the Sea of Hiuchi. Proc Nansei Reg Oceanogr Res Meet 10:35-57

Litvak MK, Leggett WC (1992) Age and size-seleccttive predation on larval fishes: the bigger-is-better hypothesis revisited. Mar Ecol Prog Ser 81:13-24

Margulies D (1993) Assessment of the nutritional condition of larval and early juvenile tuna and Spanish mackerel

Editorial responsibility: Otto Kinne (Editor-in-Chief), Oldendorf/Luhe, Germany
(Pisces: Scombridae) in the Panama Bight. Mar Biol 115: 317-330

Meekan MG, Fortier L (1996) Selection for fast growth during the larval life of Atlantic cod Gadus morhua on the Scotian Shelf. Mar Ecol Prog Ser 137:25-37

Post JR, Prankevicius AB (1987) Size-selective mortality in young-of-the-year yellow perch (Perca flavescens): evidence from otolith microstructure. Can J Fish Aquat Sci 44:1840-1847

Shoji J, Tanaka M (2001) Strong piscivory of Japanese Spanish mackerel larvae from their first feeding. J Fish Biol 59: 1682-1685

Shoji J, Tanaka M (2003) Larval abundance, growth, and recruitment of Japanese Spanish mackerel Scomberomorus niphonius in the Seto Inland Sea, Japan. In: Browman HI, Skiftesvik AB (eds) The big fish bang. Institute of Marine Research, Bergen, p 395-404

Shoji J, Tanaka M (2004) Effect of prey concentration on growth of piscivorous Japanese Spanish mackerel Scomberomorus niphonius larvae in the Seto Inland Sea, Japan. J Appl Ichthyol 20:271-275

Shoji J, Tanaka M (2005a) Distribution, feeding and growth of Japanese Spanish mackerel (Scomberomorus niphonius) larvae in the central Seto Inland Sea, Japan. Fish Bull 103: 371-379

Shoji J, Tanaka M (2005b) Larval growth and mortality of Japanese Spanish mackerel (Scomberomorus niphonius) in the central Seto Inland Sea, Japan. J Mar Biol Assoc UK 85:1255-1261

Shoji J, Aoyama M, Fujimoto H, Iwamoto A, Tanaka M (2002) Susceptibility to starvation by piscivorous Japanese Spanish mackerel Scomberomorus niphonius (Scombridae) larvae at first feeding. Fish Sci 68:59-64

Shoji J, Masuda R, Yamashita Y, Tanaka M (2005) Effect of low dissolved oxygen concentrations on behavior and predation rates on fish larvae by moon jellyfish Aurelia aurita and by a juvenile piscivore, Spanish mackerel Scomberomorus niphonius. Mar Biol 147:863-868

Sirois P, Dodson JJ (2000) Critical periods and growth-dependent survival of larvae of an estuarine fish, the rainbow smelt Osmerus mordax. Mar Ecol Prog Ser 203:233-245

Takahashi M, Watanabe Y (2004) Growth rate-dependent recruitment of Japanese anchovy Engraulis japonicus in the Kuroshio-Oyashio transitional waters. Mar Ecol Prog Ser 266:227-238

Takasuka A, Aoki I, Mitani I (2003) Evidence of growth-selective predation on larval Japanese anchovy Engraulis japonicus in Sagami Bay. Mar Ecol Prog Ser 252:223-238

Takasuka A, Aoki I, Mitani I (2004) Three synergistic growthrelated mechanisms in the short-term survival of larval Japanese anchovy Engraulis japonicus in Sagami Bay. Mar Ecol Prog Ser 270:217-228

Vigliola L, Meekan MG (2002) Size at hatching and planktonic growth determine post-settlement survivorship of a coral reef fish. Oecologia 131:89-93

Watanabe Y, Kuroki T (1997) Asymptotic growth trajectories of larval sardine (Sardinops melanostictus) in the coastal waters off central Japan. Mar Biol 127:369-378

Watanabe Y, Zenitani H, Kimura R (1995) Population decline of the Japanese sardine Sardinops melanostictus owing to recruitment failures. Can J Fish Aquat Sci 52:1609-1616

Yanagi T, Higuchi A (1979) Residual flow of the Seto Inland Sea. Bull Coast Oceanogr 16:123-127

Submitted: September 20, 2005; Accepted: February 10, 2006 Proofs received from author(s): August 10, 2006 